\section{Still not alert}

\section{Tsunami preparations in the Indian Ocean remain inadequate.}

A $t$ the end of June, the United Nations Educational, Scientific and Cultural Organization (UNESCO) announced that the Indian Ocean Tsunami Warning System was "up and running". Yet on 17 July, a tsunami in Indonesia killed more than 550 people. These events demonstrate a continuing disconnect between the rhetoric of international organizations and the reality on the ground.

In contrast to the Indian Ocean tsunami that killed almost 300,000 people in December 2004, Indonesian authorities this time received a warning from the Pacific Tsunami Warning Center. But the government did nothing with the information, fearing, according to Kusmayanto Kadiman, Indonesia's science minister, that raising a false alarm would cause unnecessary panic.

Indonesia's response to the latest disaster reflects the fact that, in the rush for action that followed the 2004 tsunami, too much emphasis has been put on the expansion of the high-tech early warning system, and not enough on improving local preparedness.

This tsunami hit the Indonesian island of Java in the afternoon, when beaches were crowded with tourists - about 40 minutes after the warning was issued. That left plenty of opportunity for evacuation, if there had been sirens, for example, or if muezzins in the local mosques were ready to warn people, or if the population knew better how to recognize the ground or sea movements that presage a tsunami.
The problem is by no means confined to Indonesia. Earthquakes as far apart as Tonga and Greece earlier this year might each have generated tsunamis, but in neither case were warnings issued to the public. In Tonga the authorities blamed an ill-functioning fax machine.

The managing board of the Indian Ocean warning system, which meets next week in Bali, must continue to implement its still-incomplete system - but must also concentrate on ensuring that countries in the region get the right advice on how to make use of such warnings.

When the Java tsunami struck, it took the Pacific Ocean warning system only a few min-
"Too much emphasis has been put on the expansion of the high-tech early warning system, and not enough on improving local preparedness." utes to respond with a warning. That time could be reduced marginally if there were more seismic stations, but what really matters now is improving national emergency management in countries such as Indonesia. UNESCO must press governments to implement better disaster planning, and, wherever possible, it should get more actively involved in tackling inadequacies itself.

If more local scientists were trained in tsunami modelling and forecasting they could advise local communities on simple actions to protect residents from tsunami-generating earthquakes. Some 60 scientists from 18 Indian Ocean nations have, for example, attended courses in Hawaii on how to produce inundation maps for warning guidance. It is through initiatives like that - ones that build local expertise from the ground up - that the death toll from future tsunamis may be minimized.

\section{Let's replicate}

\section{Post-publication follow-up evolves.}

T he replication of research results is a linchpin of the scientific process. But it isn't always done the way a layperson might expect - by replicating a previous experiment, step-by-step, in a different lab. Instead, validation of research results can take different forms in different disciplines. And as we report on page 344, changes in scientific publishing could herald a new era of open, interactive communication in which research findings are tested.

The practice of replication is already more diverse, and less cleancut, than is commonly realized. Funding agencies won't normally pay for the direct repetition of published work. In some disciplines, fresh work that builds on a published result will involve fully replicating the work that led to that result. In others, including many branches of biology, scientists see the process as validation, rather than replication. The expectation isn't necessarily that another scientist will reproduce exactly what they did, but that the data and methodology are strong enough to withstand inferences and have new experiments built upon them.

Whereas outside observers may think that all science can, and should, be reproduced, most scientists aim to confirm and extend published conclusions. That is a significantly different objective, and may be accomplished most compellingly using a different experimental approach, in pursuit of the answer to a related but separate question. This allows investigators to get around the practical difficulties of replication, such as the fact that materials or animals are never truly identical. Because of these difficulties, failed attempts to perform an exact replication of the data from a multivariable experimental system do not automatically invalidate the conclusions of the original study.

However, the interrogation of previously published results remains an essential part of science. Too often in the past, failure to achieve successful replication has left unsatisfactory research in a kind of helpless limbo. Such non-replication may be the subject of late-night arguments at scientific meetings, but is unlikely ever to be published, or even submitted for publication. Indeed, in many disciplines, it is difficult to raise concerns about an initial result in a public forum without this being construed as a full-frontal assault on the original authors' integrity.

But publishing is changing, and the idea of a scientific paper as a self-contained and unalterable body of work is gradually becoming obsolete. In some disciplines (physicists have led the way, through arXiv), scientific results are already subject to what amounts to an open-ended peer-review process, in which colleagues can continue to criticize and discuss the contents of a paper, for as long as it takes. That, rather than the current, sometimes awkward silence, is the way ahead. 